Korean J Ophthalmol 2020;34(5):416-417 https://doi.org/10.3341/kjo.2020.0072

\section{Rare Case of Lymphoepithelioma-like Carcinoma of the Eyelid}

\section{Dear Editor,}

Swanson et. al. [1] first described lymphoepithelioma-like carcinoma (LELC) as a rare, cutaneous neoplasm that usually presents with a cutaneous nodule covered by an intact epidermis. LELC ocular adnexa is extremely rare and only 6 cases of eyelid LELC have been previously reported to our knowledge, but none of these cases were reported in Korea [2-4]. Thus, here we report the first case of eyelid LELC in a Korean patient.

A 51-year-old female visited our hospital with a recurrent, hyperemic mass on the center of her left upper eyelid.
She was previously diagnosed with chalazion at a local clinic and was recommended to use oral antibiotics, but without improvement.

On slit lamp examination, a pinkish elevated mass was observed at the center of her left upper eyelid. Cilia were lost in the mass and tarsus around the mass was hyperemic (Fig. 1A, 1B). She underwent incisional biopsy and the pathologic diagnosis was poorly differentiated squamous cell carcinoma, basaloid type. However, we suspected sebaceous carcinoma based on the abnormal tarsal appearance and performed conjunctival mapping biopsy that revealed no tumor involvement.

We performed wide surgical excision of the left upper eyelid mass and the residual eyelid defect was reconstructed with a reverse Hughes flap, periosteal flap, muscle advancement flap, and full-thickness skin graft (Fig. 1C, 1D). On pathologic examination, the tumor consisted of sheets of malignant cells with vesicular nuclei, prominent nucleo-
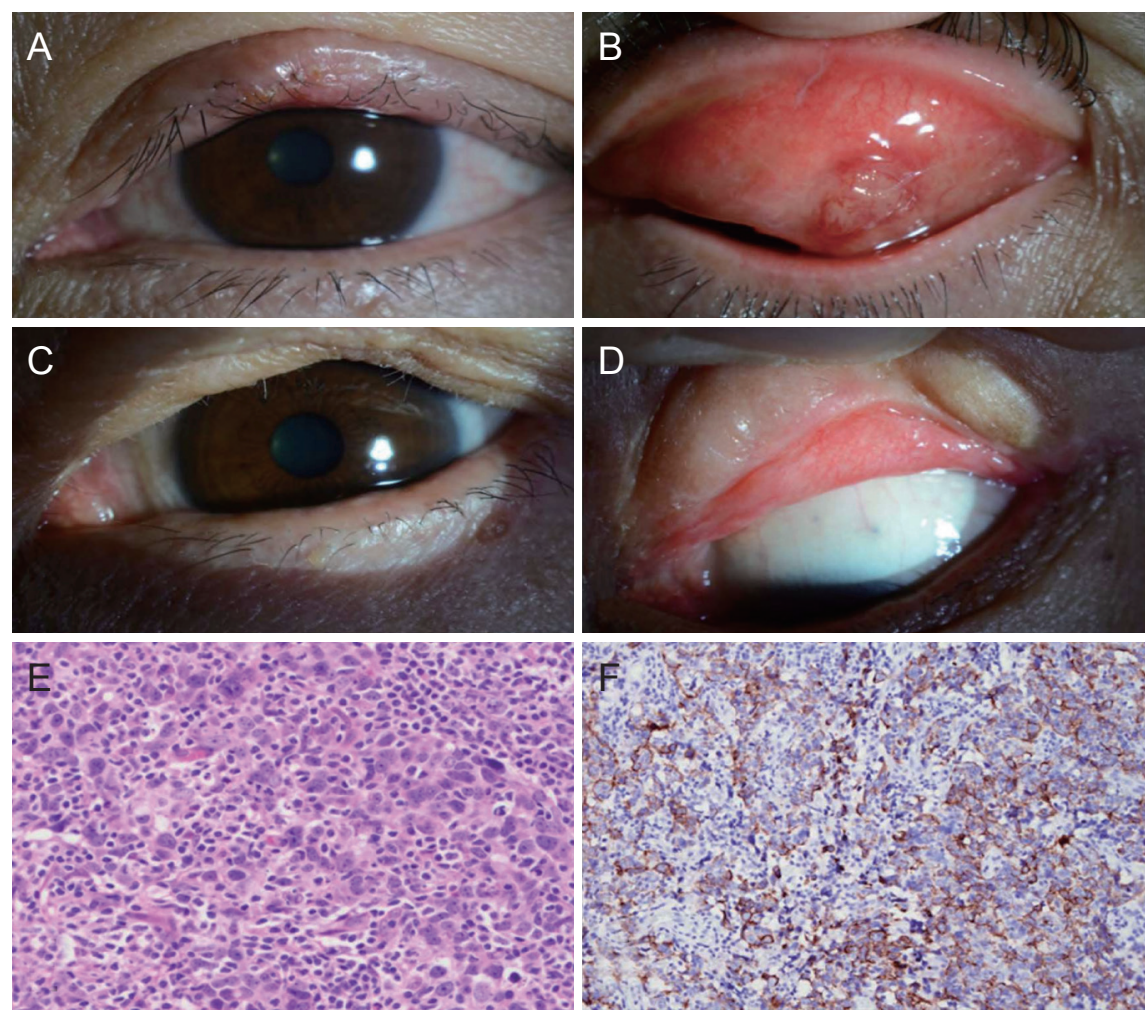

Fig. 1. Lymphoepithelioma-like carcinoma of the eyelid. (A,B) Photograph of the patient's eyelid at the time of her first visit. $(C, D)$ Photograph of the patient's eye after complete excision of lymphoepithelioma-like carcinoma. (E,F) Histopathological and immunohistochemical findings. (E) The tumor consists of sheets of malignant cells with vesicular nuclei, prominent nucleoli, and indistinct cytoplasmic borders imparting a syncytial appearance; tumor infiltrating lymphocytes are conspicuous $(\mathrm{H} \& \mathrm{E}, \times 400)$. (F) Immunostaining for cytokeratin reveals a meshwork pattern of tumor cells $(\times 200)$. Informed consent for publication of the clinical images was obtained from the patient.

Received: May 27, 2020 Final revision: June 21, 2020 Accepted: June 22, 2020

(C) 2020 The Korean Ophthalmological Society

This is an Open Access article distributed under the terms of the Creative Commons Attribution Non-Commercial License (http://creativecommons.org/licenses /by-nc/3.0/) which permits unrestricted non-commercial use, distribution, and reproduction in any medium, provided the original work is properly cited. 
li, and indistinct cytoplasmic borders with a syncytial appearance. The tumor was further characterized by lymphoid cells that broke the tumor up into tiny aggregates, which made it difficult to identify the epithelial nature of the neoplasm (Fig. 1E). There was no evidence of sebaceous tumor cell differentiation. Immunostaining for cytokeratin showed tumor cell positivity, consistent with LELC (Fig. 1F). We performed in situ hybridization for Epstein-Barr virus-encoded small RNA; however, the result was negative.

The patient was followed up for 4 years with annual ophthalmic examination and computed tomography imaging, and 4 years after the surgery, head and neck computed tomography imaging revealed a $1.5-\mathrm{cm}$ enhancing mass in the left upper parotid gland. Sono-guided gun biopsy showed metastatic LELC and she underwent left total parotidectomy with supraomohyoid neck dissection followed by postoperative radiotherapy. She has been disease-free for over 1 year.

As far as we know, only three cases of primary eyelid LELC have been reported. All three patients underwent surgical treatment, and one of them had recurrence and metastasis; she was a 43-year old Chinese woman who had LELC in the left lower eyelid. Two years after surgery, orbital, supraclavicular lymph node, and parotid lymph node recurrence de.

\section{Jounghan Kim}

Department of Ophthalmology, Seoul National University

Hospital, Seoul, Korea
Hyojin Kim

Department of Pathology, Seoul National University Bundang Hospital, Seongnam, Korea

\section{Namju Kim}

Department of Ophthalmology, Seoul National University Bundang Hospital, Seongnam, Korea

E-mail: kimnamju@snubh.org

\section{Conflict of Interest}

No potential conflict of interest relevant to this article was reported.

\section{References}

1. Swanson SA, Cooper PH, Mills SE, Wick MR. Lymphoepithelioma-like carcinoma of the skin. Mod Pathol 1988;1:35965

2. Blasi MA, Ventura L, Laguardia M, et al. Lymphoepithelioma-like carcinoma involving the lacrimal gland and infiltrating the eyelids. Eur J Ophthalmol 2011;21:320-3.

3. Maruyama M, Miyauchi S, Ohtsuka H, Miki Y. Lymphoepithelioma-like carcinoma originating on the eyelid. J Dermatol 1995;22:218-22.

4. Qiu B, Lin YB, Cai QQ, et al. Primary lymphoepithelioma-like carcinoma of ocular adnexa: clinicopathologic features and treatment. Curr Oncol 2013;20:e113-22. 